\title{
Clinical study of ectopic pregnancy
}

\author{
Meenakshi T. Chate ${ }^{1 *}$, Bhagyashree Chate ${ }^{2}$, Kranti Chate ${ }^{3}$
}

\begin{abstract}
${ }^{1}$ Department of Obstetrics and Gynecology, ${ }^{2}$ Department of Pathology, S.R.T.R.M.C Ambajogai, Maharashtra, India ${ }^{3}$ Department of Anesthesia, GMC Miraj, Maharashtra, India
\end{abstract}

Received: 26 May 2017

Accepted: 24 June 2017

\section{*Correspondence:}

Dr. Meenakshi T. Chate,

E-mail: chate.meenakshi8@gmail.com

Copyright: (C) the author(s), publisher and licensee Medip Academy. This is an open-access article distributed under the terms of the Creative Commons Attribution Non-Commercial License, which permits unrestricted non-commercial use, distribution, and reproduction in any medium, provided the original work is properly cited.

\begin{abstract}
Background: Ectopic pregnancy is pregnancy that develops following implantation anywhere other than the endometrial cavity of uterus. Objective of present study was to investigate the risk factors, clinical presentation and sites of ectopic pregnancy along with management and assessment of risk of maternal mortality and morbidity.

Methods: The study was undertaken at Dr. Shankar Rao Chavhan Government Medical College and Guru Govind singhji hospital, Nanded between December 2012 and May 2014 after obtaining clearance from the Hospital Ethical Committee.

Results: Maximum incidence of tubal gestation occurred between the age group of 21-25 years. Greater incidence was noted in multiparous woman. Tubectomy was the most common risk factor seen in $23.65 \%$ cases. The most common symptom observed is abdominal pain seen in $92.47 \%$ cases. The most common site of ectopic was ampulla seen in $51.61 \%$ cases. The most common mode of presentation was rupture seen in 71 cases about $76.35 \%$ cases. Unilateral salpingectomy was done in 70 cases about $75.26 \%$ cases.

Conclusions: Since ectopic pregnancy remains a gynecological catastrophe in countries and a major challenge to the reproductive performance of women worldwide, it should be considered a relevant public health issue. With its rising incidence, which is likely to continue increasing because of the various factors discussed, it is necessary to devise means of early detection and treatment.
\end{abstract}

Keywords: Ectopic pregnancy, UPT (Urine pregnancy test)

\section{INTRODUCTION}

Ectopic pregnancy is pregnancy that develops following implantation anywhere other than the endometrial cavity of uterus. ${ }^{1}$ Ectopic is derived from a Greek word "EXTOPOS" meaning "out of place".

Ectopic pregnancy is one of the leading causes of maternal mortality in first trimester but it is also one of the conditions threatening the fertility of the patient. This higher danger to life results from massive bleeding that occurs when these pregnancies rupture. These abnormal pregnancy locations, unlike uterus, cannot expand enough to fit the growing embryo; thus, these structures eventually rupture causing bleeding.

Over the past three decades, in many countries; the incidence of ectopic showed an initial increase followed by a decrease which has been observed recently. The likely causes of this increase in incidence was prevalence of sexually transmitted disease, use of intra-uterine contraceptive device, tubal sterilization, tubal reconstructive surgery, assisted reproductive techniques and probably early diagnosis of some cases which were 
destined for early resolution. The recent decline may be attributed to decline in the prevalence of sexually transmitted diseases like Chlamydia and change in use of intrauterine contraceptive devices. ${ }^{2}$

The incidence of ectopic pregnancy varies from 1 in 300 to 1 in 150 .The incidence of ectopic has steadily risen since 1970 and now accounts for approximately $2 \%$ of all pregnancies; the risk of death from ectopic pregnancy has declined by $90 \%{ }^{3}$

Ectopic pregnancy is often proclaimed as the great masquerader, as the diagnosis is complicated by a wide spectrum of clinical presentation from asymptomatic cases to haemoperitoneum and shock. The classical clinical triad of amenorrhea, bleeding per vaginum and lower abdominal pain is present in less than $50 \%$ of cases $^{4}$.

The cause of death in cases of ectopic pregnancy are shock, acute renal failure, disseminated intravascular coagulopathy, pulmonary embolism, sepsis and multiple organ failure. The study aims on determining risk factors, clinical presentation, diagnostic modalities and various treatment options which might help in guiding principle in diagnosis and management cases of ectopic pregnancies.

\section{METHODS}

The study was undertaken at Dr. Shankar Rao Chavhan Government Medical College and Guru Govind singhji hospital, Nanded between December -2012 and May2014 after obtaining clearance from the Hospital Ethical Committee.

All diagnosed cases of ectopic pregnancy were enrolled in the study. Detailed history and clinical evaluation was done. Information was collected in a pretested proforma.

\section{Inclusion criteria}

All diagnosed cases of ectopic pregnancy admitted to Dr. Shankar Rao Chavhan and Government Medical College and Guru Gobind Singh Ji hospital, Nanded during the $1 \frac{1 / 2}{2}$ years study period.

\section{Exclusion criteria}

All intrauterine pregnancies and ectopic pregnancies managed by medical or expectant management were excluded.

\section{RESULTS}

$\mathrm{T}$ In the present study we found that the most common age group in which ectopic was seen in the present study was $21-25$ years $(36.55 \%)$; this may be attributed to the fact this time period is maximum fertile period and use of contraception is infrequent and occasional. This also may be because most young unmarried females with unintended pregnancies often procure unsafe abortions, which subsequently predisposes them to having an ectopic gestation in future pregnancies ectopic pregnancy can occur at any parity with variable clinical presentations.

Table 1: Ectopic pregnancy in relation to age.

\begin{tabular}{|lll|}
\hline Age group (years) & No. of cases & $\%$ \\
\hline $15-20$ & 5 & 5.38 \\
\hline $21-25$ & 34 & 36.55 \\
\hline $26-30$ & 32 & 34.41 \\
\hline $31-35$ & 16 & 17.20 \\
\hline $36-40$ & 3 & 3.23 \\
\hline $41-45$ & 3 & 3.23 \\
\hline Total & 93 & 100 \\
\hline
\end{tabular}

Table 2: Distribution of cases based on parity.

\begin{tabular}{|l|ll|}
\hline Parity & No. of cases & $\%$ \\
\hline Nullipara & 22 & 23.67 \\
\hline Primipara & 23 & 24.73 \\
\hline Multipara & 48 & 51.60 \\
\hline
\end{tabular}

We observed maximum incidence of Ectopic pregnancy was in Multipara i.e. $51.60 \%$ followed by primipara i.e. $24.73 \%$ followed by nullipara i.e. $23.67 \%$. This increased incidence in multipara might be due to increased sexual life, increased incidence of pelvic inflammatory disease and use of contraception in form of IUCDs and progesterone only pills.

Table 3: Ectopic pregnancy in relation to risk factors.

\begin{tabular}{|lll|}
\hline Risk factors & No. of cases & $\%$ \\
\hline None & 36 & 38.71 \\
\hline Tubectomy & 22 & 23.65 \\
\hline Iucd & 6 & 6.45 \\
\hline Infertility & 19 & 20.43 \\
\hline Pid & 10 & 10.76 \\
\hline Total & 93 & 100 \\
\hline
\end{tabular}

In the present study, the maximum incidence of ectopic was seen in patients who had no apparent risk factors $(38.71 \%)$. Tubectomy was the most common risk factor in the present study $(23.65 \%)$.

Table 4: Mode of presentation.

\begin{tabular}{|lll|}
\hline Symptoms & No. of cases & $\%$ \\
\hline Amenorrhea & 72 & 77.41 \\
\hline Pain in abdomen & 86 & 92.47 \\
\hline Bleeding per vaginum & 54 & 58.06 \\
\hline
\end{tabular}

In present study, abdominal pain and amenorrhea was present in $92.47 \%$ and $77.41 \%$ cases suggestive of most common presentation of patient with ectopic pregnancy. In the present $22.58 \%$ of cases were without history of 
amenorrhea suggesting presentation of ectopic pregnancy before missed period.

Table 5: Site of ectopic pregnancy on laparotomy.

\begin{tabular}{|lll|}
\hline Site & No. of cases & $\%$ \\
\hline Ampulla & 48 & 51.61 \\
\hline Isthmus & 10 & 10.76 \\
\hline Ovary & 9 & 9.67 \\
\hline Fimbria & 18 & 19.35 \\
\hline Cornual & 8 & 8.61 \\
\hline Ampulla+isthmus & 0 & 0 \\
\hline Total & 93 & 100 \\
\hline
\end{tabular}

Commonest site for ectopic pregnancy is ampulla in present study accounting for $51.61 \%$ cases followed by fimbria in $19.35 \%$ cases. Isthmus was next most common site in $10.76 \%$ cases. Ovary and corneal involvement was seen in $9.67 \%$ and $8.61 \%$.

Table 6: Condition of tube.

\begin{tabular}{|lll|}
\hline Condition of tube & No. of cases & $\%$ \\
\hline Rupture & 71 & 76.35 \\
\hline Unrupture & 7 & 7.53 \\
\hline Tubal abortion & 15 & 16.12 \\
\hline Total & 93 & 100 \\
\hline
\end{tabular}

In the present study, the incidence of rupture was $76.35 \%$ cases tubal abortion was seen in $16.12 \%$ followed by unruptured ectopic pregnancies in $7.53 \%$.

Table 7: Procedure done.

\begin{tabular}{|lll|}
\hline Procedure & No. of cases & $\%$ \\
\hline Salpingostomy & 1 & 1.08 \\
\hline Unilateral salpingectomy & 70 & 75.26 \\
\hline Bilateral salpingectomy & 0 & 0 \\
\hline $\begin{array}{l}\text { Unilateral salpingo- } \\
\text { oopherectomy }\end{array}$ & 20 & 21.51 \\
\hline $\begin{array}{l}\text { Salpingoopherectomy with } \\
\text { contra-lateral tubal ligation }\end{array}$ & 0 & 0 \\
\hline $\begin{array}{l}\text { Laparoscopic salpingostomy } \\
\text { Laparoscopic salpingectomy }\end{array}$ & 0 & 0 \\
\hline $\begin{array}{l}\text { Laparoscopic } \\
\text { Salpingoopherectomy }\end{array}$ & 0 & 2.15 \\
\hline $\begin{array}{l}\text { Laparoscopic bilateral } \\
\text { Salpingo-opherectomy }\end{array}$ & 0 & 0 \\
\hline
\end{tabular}

Salpingectomy was the commonest life-saving surgical procedure performed in the studied subjects, since most of the cases were ruptured ectopic pregnancies with massive hem peritoneum.

In the present study, unilateral salpingectomy was done in $75.26 \%$ cases followed by unilateral salpingooopherectomy in $21.51 \%$ cases. Laparoscopic salpingectomy was done in $2.15 \%$ cases. Salpingostomy was done in $1.08 \%$ cases.

\section{DISCUSSION}

\section{Age group}

In the present study, we found that the most common age group in which ectopic was seen in the present study was 21-25 years $(36.55 \%)$. Similarly, reported by Panchal D et al the maximum incidence was seen in the age group of 21-30 years which was $71.66 \% .^{5}$ Shetty et al also reported maximum incidence of ectopic in age group of 25-30 years i.e 74.2\%. ${ }^{6}$ Gaddagi et al reported $70.2 \%$ of cases belonged to 21-30 years of age; while Porwal et al reported an incidence of $47.5 \%$ in age group of 21-25 years. $^{7,8}$

\section{Parity}

We observed maximum incidence of Ectopic pregnancy was in multipara i.e. $51.60 \%$ followed by primipara i.e. $24.73 \%$ followed by nullipara i.e. $23.67 \%$. Multiparous woman was found to be more prone to ectopic pregnancy in Gaddagi et al i.e. 62.2\%; Shetty et al i.e. around $83.9 \%$ and Khaleeque et al study about $61 \%$.,7,9

\section{Risk factors}

In the present study, the maximum incidence of ectopic was seen in patients who had no apparent risk factors (38.71\%). Similarly, Gaddagi et al found $37.83 \%$ had no apparent risk factors. ${ }^{7}$

\section{Mode of presentation}

In present study, abdominal pain and amenorrhea was present in $92.47 \%$ and $77.41 \%$ cases suggestive of most common presentation of patient with ectopic pregnancy. Shetty $\mathrm{S}$ et al observed the commonest symptoms were abdominal pain (80.6\%), amenorrhea $(77.4 \%)$ and abnormal vaginal bleeding $(61.3 \%)$ cases. ${ }^{6}$ Gaddagi et al observed that a majority of the cases presented with pain in the abdomen (89.2\% of cases); amenorrhea was seen in $75.7 \%$ cases and spotting per vaginum in $43.2 \%$ cases Porwal et al noted that maximum $(87.5 \%)$ cases of ectopic pregnancies reported with pain in abdomen.,

\section{Site of ectopic}

Commonest site for ectopic pregnancy is ampulla in present study accounting for $51.61 \%$ cases followed by fimbria in $19.35 \%$ cases. Isthmus was next most common site in $10.76 \%$ cases. Ovary and corneal involvement was seen in $9.67 \%$ and $8.61 \%$.

According to Shetty $\mathrm{S}$ the commonest site of location of the ectopic pregnancy was in the ampulla of the fallopian tube seen in $45.2 \%$ cases. ${ }^{6}$ Similar findings were noted by Gaddagi $\mathrm{R}$ et al i.e. majority of the cases were ampulla pregnancies $(69.7 \%){ }^{7}$ Porwal $S$ et al observed that ampullary portion of tubes $(40 \%)$ and isthmus $(32.5 \%)$ to be most common sites. ${ }^{8}$ 


\section{Condition of tube}

In the present study, the incidence of rupture was $76.35 \%$ cases Tubal abortion was seen in $16.12 \%$ followed by unruptured ectopic pregnancies in $7.53 \%$. Similar findings were noted by Gaddadi $\mathrm{R}$ et al $78.3 \%$ showed a ruptured ectopic pregnancy on laparotomy. ${ }^{7}$ Tubal abortion was seen in 4 cases and an unruptured ectopic pregnancy in 3 cases. Shetty et al unruptured ectopic and tubal abortion in $12.9 \%$ cases. $^{7}$

\section{Procedure done}

In the present study, unilateral salpingectomy was done in $75.26 \%$ cases followed by unilateral salpingooopherectomy in $21.51 \%$ cases. Laparoscopic salpingectomy was done in $2.15 \%$ cases.Salpingostomy was done in $1.08 \%$ cases.

Panchal D et al noted partial salpingectomy was done in $21.66 \%$ and total salpingectomy was done in $61.66 \%$ cases, Shetty et al observed the most common surgery done was unilateral salpingectomy in 28 (90.3\%), salpingo-oophorectomy in $2(6.5 \%)$ and salpingostomy in $1(3.2 \%))^{5,6}$ Porwal et al noted the most frequent procedure in cases is total salpingectomy $(45 \%)$ and salpingoophorectomy in $32.5 \%$ of cases. ${ }^{8}$ Gaddagi et al the most common procedure which was done was salpingectomy in $51.4 \%$ of the cases, followed by salpingo-oophorectomy in another $13.5 \%$ of the cases. ${ }^{7}$ In $5.4 \%$ of the cases (i.e. 2 cases) total abdominal hysterectomy was done. Both these cases were cornual pregnancies.

\section{CONCLUSION}

Since ectopic pregnancy remains a gynecological catastrophe in countries and a major challenge to the reproductive performance of women worldwide, it should be considered a relevant public health issue. With its rising incidence, which is likely to continue increasing because of the various factors discussed, it is necessary to devise means of early detection and treatment. This could be achieved by providing adequate materials, manpower and equipment of health facilities, as well as a prompt and efficient referral system, good access roads, and efficient transportation, which will ensure early presentation in hospitals and prompt management of cases.
Health education on safer sex and provision of familyplanning services, such as condoms and other barrier contraceptives, will help prevent sexually transmitted infection and unwanted pregnancies, thereby reducing the incidence of pelvic infection and postabortal complications. These interventions are expected to reduce the incidence of ectopic pregnancy and the consequent loss of reproductive potential, as has been recorded in some advanced countries of the world.

Funding: No funding sources

Conflict of interest: None declared

Ethical approval: The study was approved by the Institutional Ethics Committee

\section{REFERENCES}

1. TeLinde. Operative Gynecology. 10th Ed. Lippincott - Raven, Philadelphia;1997:798.

2. Anon. Ectopic pregnancies: United states 1990-92. Morb Mortal Wkly Rep. 1995;44:46-8.

3. Shetty VH, Some Gowda LM. Role of ultrasonography in diagnosis of ectopic pregnancy with clinical analysis and management in tertiary care hospital. J Obstet Gynaecol India. 2014;64(5):354.

4. Arora R, Rathore AM, Habeebullah S, Oumachigui A. Ectopic pregnancy changing trends. JIMA.1998;96:53-7.

5. 5Panchal D, Vaishnav G, Solanki K. Study of Management in Patient with Ectopic Pregnancy. NJIRM. 2011;2(3):91-4.

6. Shetty S, Shetty A. A clinical study of ectopic pregnancies in a tertiary care hospital of mangalore, India. Innov J Med Health Sci. 2014;4(1)305-9.

7. Gaddagi RA, Chandrashekhar AP. A clinical study of ectopic pregnancy. J Clin Diag Res. 2012;6:867-9.

8. Gupta R, Porwal S, Swarnkar M, Sharma N, Maheshwari P. Incidence, trends and risk factors for Ectopic Pregnancies in a tertiary care hospital of Rajasthan. J Pharm Biomed Sci. 2012;16(07):1-3.

9. Khaleeque F, Siddiqui RI, Jafarey SN. Ectopic pregnancies: a three year study. J Pak Med Assoc. 2001;51:240-3.

Cite this article as: Chate MT, Chate $\mathrm{B}$, Chate. Clinical study of ectopic pregnancy. Int J Reprod Contracept Obstet Gynecol 2017;6:3498-3501. 